\title{
Desenvolvimento de instrumentação para aumento de rugosidade de maneira controlada na fabricação de filmes ultrafinos automontados.
}

\section{Diego S. Claro, Antonio Riul Jr, Varlei Rodrigues}

\section{Resumo}

Neste trabalho tentamos controlar o grau de molhabilidade de uma interface através da relação hierárquica entre micro e nanoestruturas modificando a topologia de superfície com um filme ultrafino nanoestruturado através da técnica de automontagem por adsorção física (LbL, do inglês "layer-by-layer"). Para isso, tentamos inserir vibrações mecânicas com frequência e amplitude controladas ao longo do processo fabricação de filmes LbL. Os resultados indicaram que as vibrações não apresentaram efeito significativo na molhabilidade das interfaces cobertas com as estruturas LbL.

\section{Palavras-chave:}

Nanoestruturação, automação, controle de rugosidade

\section{Introdução}

A técnica de automontagem por adsorção física (LbL, do inglês "layer-by-layer) é baseada na adsorção espontânea de moléculas em solução aquosa em um substrato sólido por meio de interações moleculares não covalentes. O filme nanoestruturado é formado camada a camada intercalando materiais com grupos carregados positiva e negativamente [1]. Por ser uma técnica versátil, é possível acoplar outras características ao filme ultrafino, como funcionalidades complexas que interferem no grau de molhabilidade da superfície [2]. A molhabilidade de superfícies é controlada tanto pela composição química quanto pela rugosidade [3], o que nos motivou neste trabalho a manipularmos a natureza de topologia dos filmes com vibrações mecânicas de forma controlada por meio de um dispositivo eletromecânico.

\section{Experimental}

Para o estudo da influência da vibração mecânica durante o processo de fabricação três conjuntos diferentes de filmes foram feitos, cada um com seis amostras:

- (PAH / CuTsPc) com 10 bicamadas;

- (GPAH-PEI / GPSS-PAA) com 10 bicamadas;

- (GPAH-PEI / GPSS-PAA) com 60 bicamadas.

Foi medido o ângulo de contato para a determinação da molhabilidade de superfícies cobertas com os filmes LbL, e para a determinação da rugosidade as superfícies foram caracterizadas por microscopia de força atômica (AFM, do inglês Atomic Force Microscopy). Adicionalmente, o crescimento dos filmes $\mathrm{LbL}$ foi acompanhado por meio da técnica de espectroscopia UVVis.

Um sinal de $20 \mathrm{~Hz}$ e $200 \mathrm{~Hz}$ com mesma amplitude foram acoplados em um braço mecânico controlado por Arduino e feito em nosso grupo de pesquisa para realizar de maneira automática $o$ crescimento dos filmes LbL.

\section{Resultados e Discussões}

O valor encontrado para o ângulo de contato para o primeiro conjunto de amostras foi de aproximadamente $40^{\circ}$, mesmo valor para as amostras feitas da forma convencional (sem vibração mecânica acoplada durante o processo de fabricação). Além disso, as rugosidades encontradas foram todas da mesma ordem de grandeza, evidenciando que não foi possível alterar a rugosidade das nanoestruturas LbL como inicialmente planejado.

Mesmo considerando diferentes arquiteturas LbL, como filmes de (GPAH-PEI/GPSS-PAA) com 10 bicamadas, $O$ ângulo de contato continuou aproximadamente $40^{\circ}$ para todas as amostras analisadas, e rugosidades de mesma ordem de grandeza. No entanto, filmes (GPAH-PEl/GPSS-PAA) com 60 bicamadas apresentaram um ângulo de contato de aproximadamente $100^{\circ}$ para todas as amostras produzidas e também apresentaram rugosidade na mesma ordem de grandeza.

\section{Conclusão}

Foi possível concluir que a modificação não danificou a montagem dos filmes. As amostras não apresentaram uma redução em seu grau de molhabilidade. Adicionamente, foi possível perceber que o grau de molhabilidade de um filme depende do número de bicamadas depositadas. Tendo em vista os aspectos observados, pode-se concluir que a inserção de vibração mecânica a baixas frequências não altera significativamente o grau de molhabilidade das amostras.

\section{Agradecimentos}

Aos meus orientadores, Antonio Riul Jr e Varlei Rodrigues, por todo suporte.

Ao Laboratório de Multiusuários do IFGW (LAMULT), pelas medidas de AFM.

Ao Prof. Dr. José Alberto Fracassi da Silva, pelo auxílio nas medidas de ângulo de contato.

Ao CNPq pelo financiamento e confiança depositada na execução deste trabalho.

À Unicamp por toda a infraestrutura dada para a realização do trabalho.

\footnotetext{
J. J. Richardson, M. Bjornmalm, F. Caruso. Technology driven by layer-bylayer assembly of nanofilms. Science, 348,411, 2015.
}

${ }^{2}$ G. Decher. Fuzzy nanoassemblies toward layered polymeric multicomposities. Science, 277, 1232-1237, 1997.

${ }^{3}$ M. Liu, S. Wang and L. Jiang. Nature-inspired superwettability systems. Nature Reviews, 2017. 